\title{
Nanostructure and Thermal Behaviour of Liquid Crystalline Oligoester
}

\section{J. JANICKI}

Technical Academy of Bielsko-Biała, Willowa 2, 43-309 Bielsko-Biała, Poland

\begin{abstract}
The nanostructure and thermal behaviour of liquid crystalline oligoester were examined by combination of real-time synchrotron small-angle and wide-angle $\mathrm{X}$-ray scattering methods with differential scanning calorimetry. The synthesized oligoester exhibits ability to form a thermotropic mesophase. It was shown that solid crystalline state is observed in the temperature range 25 to $123^{\circ} \mathrm{C}$ and liquid crystalline state between $118-156^{\circ} \mathrm{C}$. The transition temperature determined from dynamic small-angle and wide-angle $\mathrm{X}$-ray scattering experiments agrees very well with the results obtained from differential scanning calorimetry.
\end{abstract}

PACS numbers: 87.64.Bx, 81.07.Nb, 82.35.Lr

\section{Introduction}

During the last decade, liquid crystalline polymers (LCP) have been presented as new compounds with superior properties as compared to conventional polymers. The search for melt-processable liquid crystalline polymers, which are miscible or partially miscible with conventional polymers, is still a great challenge in polymer science $[1,2]$. Thermotropic LCP usually contain rigid-rod chemical structure and therefore possess unique properties such as low melt viscosity and high modulus in the solid form, which is direction dependent. Blending of thermotropic LCP with semicrystalline thermoplastic polymers to form in situ polymer composites is very attractive because of the advantages in lowering the viscosity during processing and in reinforcing the final mechanical properties [3-5]. However, the melting temperature of liquid crystalline polymers is usually above $200^{\circ} \mathrm{C}$, which is too high for processing semicrystalline thermoplastic polymers. In order to reduce the melting and transition temperature new LCP, with flexible units in the main chain were synthesized, resulting in a lower melting temperature [6-8]. In this search for new composite materials, less attention is paid to the proper characterization of the structure of thermotropic liquid crystalline polymers. It is 
shown that an unambiguous characterization is only possible by a combination of different techniques such as small- and wide-angle X-ray scattering (SAXS, WAXS) with differential scanning calorimetry (DSC).

\section{Experimental}

\subsection{Materials}

Liquid crystalline compounds having three rings rod-like mesogen and aliphatic end groups are synthesized. The aromatic rings in the mesogen are bonded to ester groups while the aliphatic end groups, consisting of eleven carbon atoms are connected with the aromatic ring by ester bonds. The macromolecule chain of oligoester is presented in Fig. 1.

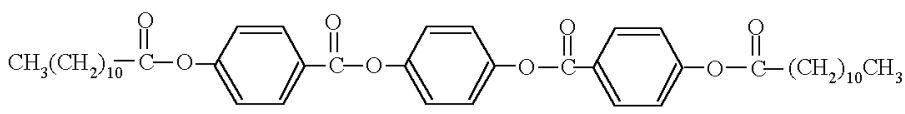

Fig. 1. The macromolecular chain of liquid crystalline oligoester.

\subsection{Methods}

The SAXS and WAXS investigations were carried out using synchrotron beamline on the X33 double focusing camera of the EMBL in Hasylab, on the storage ring DORIS III of the DESY in Hamburg at a wavelength of $0.15 \mathrm{~nm}$. The SAXS pinhole patterns of liquid crystal oligoester (LCO) were recorded using sample-detector distance of $2.8 \mathrm{~m}$ to cover the range of magnitude of the scattering vector $0.012 \leq s \leq 0.894 \mathrm{~nm}^{-1}(s=2 \sin \theta / \lambda$, where $2 \theta$ is the scattering angle and $\lambda$ is the wavelength). During the real-time measurements, SAXS and WAXS patterns were simultaneously recorded every 6 seconds giving a temperature resolution of $1^{\circ} \mathrm{C}$ per one pattern, using a standard acquisition system with two delay line detectors connected in series $[9,10]$. The range of scattering vectors was calibrated using the first nine interference orders of dry collagen with a spacing of $64 \mathrm{~nm}$. The WAXS data were collected over the angular range $11.7 \leq 2 \theta \leq 46^{\circ}$ calibrated with a silicon standard. The SAXS and WAXS intensities were normalized to the intensity of the primary beam and corrected for the detector response. Finally, an averaged melt pattern was subtracted from each curve to eliminate background scattering.

The differential scanning calorimetry measurements were carried out on a Perkin Elmer-Pyris instrument. The temperature was calibrated with the melting points of indium $\left(156.6^{\circ} \mathrm{C}\right)$ and benzophenone $\left(48^{\circ} \mathrm{C}\right)$ and the enthalpy was calibrated with indium (28.45 $\left.\mathrm{J} \mathrm{g}^{-1}\right)$. The contribution of an empty pan was subtracted from each measurement. The block surrounding the measurement units was thermostated at $-10^{\circ} \mathrm{C}$ with liquid nitrogen and the measuring cell was flushed with nitrogen gas. The heating and cooling rate of samples was $10^{\circ} \mathrm{C} / \mathrm{min}$. 


\section{Results and discussion}

Information concerning the thermal behaviour of liquid crystalline oligoester was obtained by differential scanning calorimetry. DSC heating and cooling curves of oligoester collected at the rate $10^{\circ} \mathrm{C} / \mathrm{min}$ are shown in Fig. 2. The heating curves exhibit three endothermic peaks. The first wide peak is connected with the glass transition temperature which was evaluated as $56^{\circ} \mathrm{C}$, and so-called cold crystallization which is observed during heating above the glass transition [11]. The main endothermic peak indicates the melting temperature $\left(118.7^{\circ} \mathrm{C}\right)$ and the third one the isotropization temperature $\left(156.6^{\circ} \mathrm{C}\right)$. When a cooling run is performed after initial heating, three exothermic peaks are observed. The transition temperatures and the corresponding enthalpies during heating and cooling are presented in Table.

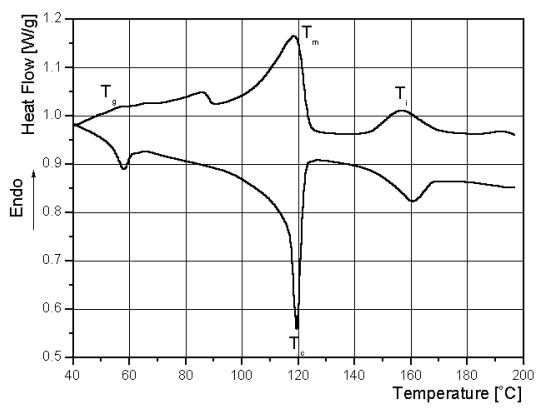

Fig. 2. DSC heating and cooling curves for LCO; $T_{\mathrm{g}}, T_{\mathrm{m}}, T_{\mathrm{c}}, T_{\mathrm{i}}$ are glass transition, melting, crystallization, and isotropization temperature, respectively.

TABLE

Enthalpies and temperatures of face transitions.

\begin{tabular}{|c|c|c|c|c|c|c|c|c|}
\hline \multicolumn{5}{|c|}{ Heating } & \multicolumn{4}{|c|}{ Cooling } \\
\hline $\begin{array}{c}T_{\mathrm{g}} \\
{\left[{ }^{\circ} \mathrm{C}\right]}\end{array}$ & $\begin{array}{c}T_{\mathrm{m}} \\
{\left[{ }^{\circ} \mathrm{C}\right]}\end{array}$ & $\begin{array}{l}\Delta H_{\mathrm{m}} \\
{[\mathrm{J} / \mathrm{g}]}\end{array}$ & $\begin{array}{c}T_{\mathrm{i}} \\
{\left[{ }^{\circ} \mathrm{C}\right]}\end{array}$ & $\begin{array}{c}\Delta H_{\mathrm{i}} \\
{[\mathrm{J} / \mathrm{g}]}\end{array}$ & $\begin{array}{c}T_{\mathrm{c}} \\
{\left[{ }^{\circ} \mathrm{C}\right]}\end{array}$ & $\begin{array}{c}\Delta H_{\mathrm{c}} \\
{[\mathrm{J} / \mathrm{g}]}\end{array}$ & $\begin{array}{c}T_{\mathrm{i}} \\
{\left[{ }^{\circ} \mathrm{C}\right]}\end{array}$ & $\begin{array}{c}\Delta H_{\mathrm{i}} \\
{[\mathrm{J} / \mathrm{g}]}\end{array}$ \\
\hline 56 & 118.7 & 17.5 & 156.6 & 2.3 & 114.8 & -11.0 & 155 & -2.6 \\
\hline
\end{tabular}

Transition temperatures of oligoester, determined from DSC during heating, are schematically shown below:

solid crystalline state $\stackrel{118^{\circ} \mathrm{C}}{\rightarrow}$ liquid crystalline state $\stackrel{156^{\circ} \mathrm{C}}{\rightarrow}$ isotropic melt. 
Based on DSC results it seems to be clear that the synthesized oligoester exhibits the ability to form the thermotropic mesophase in the temperature range $118-156^{\circ} \mathrm{C}$. The liquid crystalline state is detached both during heating and cooling, which is typical of an enantiotropic liquid crystal compound.

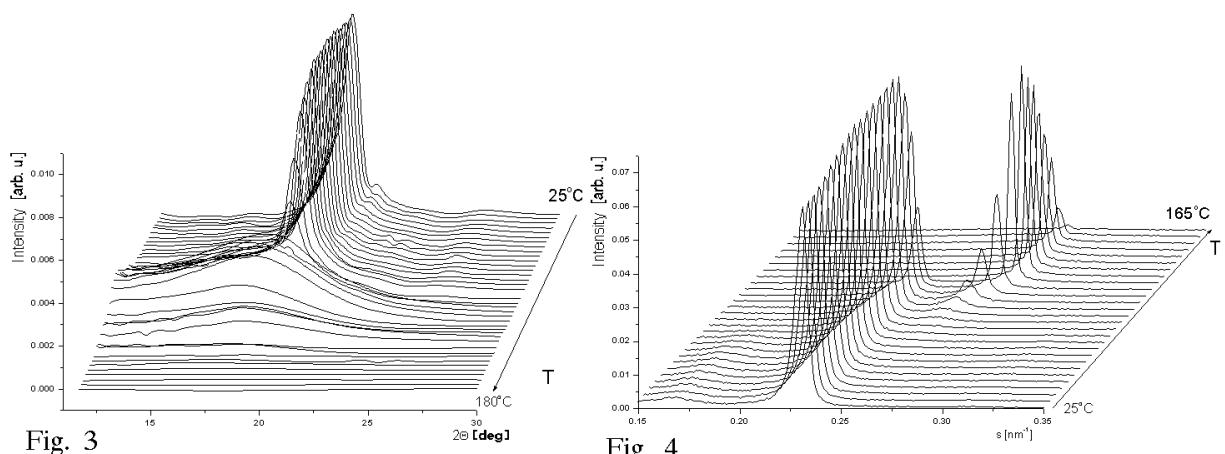

Fig. 4

Fig. 3. WAXS patterns of LCO as a function of temperature during heating.

Fig. 4. SAXS curves after background subtraction for LCO as a function of temperature during heating.

In order to determine the nanostructure of oligoester, the WAXS and SAXS real-time synchrotron experiments were performed during heating and cooling at the rate of $10^{\circ} \mathrm{C} / \mathrm{min}$. The WAXS patterns of liquid crystalline oligoester as a function of temperature during heating are presented in Fig. 3. Based on a qualitative analysis one can say that strong crystalline peaks on the WAXS curves observed from 25 to $123^{\circ} \mathrm{C}$ and very low amorphous halo indicate the well-ordered structure. Crystalline peaks disappear at $123^{\circ} \mathrm{C}$ and the scattering curve at higher temperature indicates the liquid crystalline state. More structural parameters can be obtained from the SAXS investigations. SAXS curves for oligoester during heating are shown in Fig. 4. The SAXS curves exhibit two distinct diffraction maxima, corresponding to solid crystalline state and liquid crystalline state, respectively. The angular position of the peaks is connected with the supermolecular structure with different electron densities of phases, which are separated by a repeated distance. The values of the repeated distance ( $d$-space) were evaluated using Bragg's law and are presented in Fig. 5. The values of the $d$-space calculated based on the angular position of the first SAXS peak are constant and equal to $4.33 \mathrm{~nm}$ and they are characteristic of the solid state. Based on computer modelling, the length of macromolecular chain was estimated as $4.2 \mathrm{~nm}$, which is in good agreement with the result derived from the SAXS measurements. During the melting process, macromolecular chains become more flexible and values of the $d$-space steadily decrease, which is shown in Fig. 5b. The equilibrium state appears at $123^{\circ} \mathrm{C}$ since the $d$-space is constant and equal to $3.57 \mathrm{~nm}$. The structure of LCO 
examined under polarizing optical microscope (not reported in this paper) was identified as a smectic phase. Two very sharp peaks on the SAXS curves and corresponding changes of $d$-space are characteristic of the smectic liquid crystal structure and confirm the result obtained from optical microscope observations.
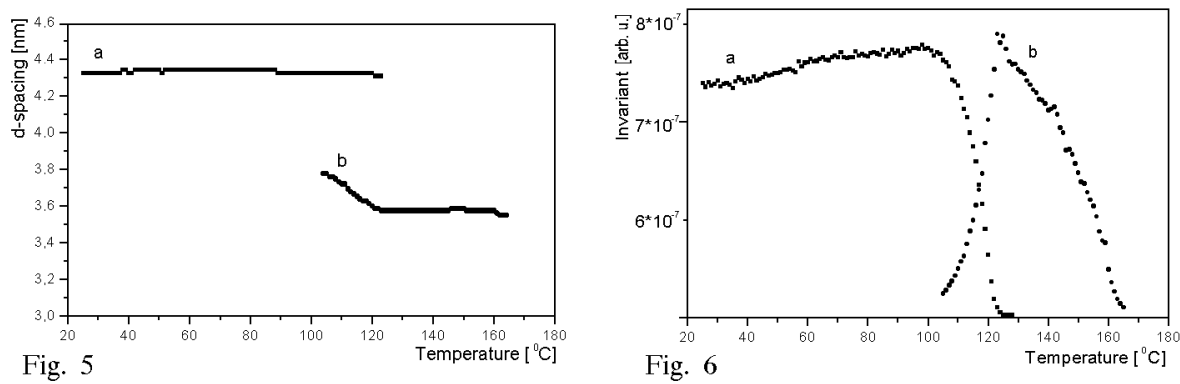

Fig. 5. The $d$-spacing values for LCO: $a$ - solid crystalline phase, $b$ - liquid crystalline phase.

Fig. 6. The invariants of LCO: $a$ - solid crystalline phase, $b$ - liquid crystalline phase.

An important parameter that can be obtained from SAXS is invariant. The invariant $Q(T)$ is the total scattering power of the system, which is independent of the size and the shape of the scattering entities and is a function of the mean square of electron density differences of phases. The invariant can be calculated by integration of the scattering intensity. The values of calculated invariants for oligoester (Fig. 6) as a function of temperature indicate two states existing in different temperature ranges. Starting from room temperature the solid crystalline phase is described by the curve $a$ in Fig. 6 . The second part of invariant function corresponds to the liquid crystalline state. In Fig. 7 the SAXS and WAXS curves are presented together for better visualization of the phase transition during heating. The transition temperatures, determined from SAXS and WAXS experiments, agree very well with obtained by DSC and support previous conclusions.

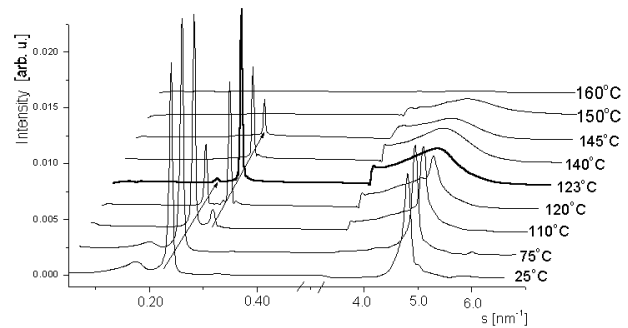

Fig. 7. The SAXS/WAXS patterns of LCO during heating.

Based on the results obtained, the following conclusions can be drawn: 
- The synthesized oligoester exhibits ability to form thermotropic mesophase.

- Solid crystalline state is observed in the temperature range from 25 to $123^{\circ} \mathrm{C}$.

- Liquid crystalline state is observed in the temperature range $118-156^{\circ} \mathrm{C}$.

- The real-time synchrotron SAXS and WAXS measurements allowed to observe the phase transition and to study the nanostructure of liquid crystal polymers.

- The smectic type of mesophase is observed for the oligoester investigated.

- Liquid crystalline oligoester can be used as a proper compound for processing with semicrystalline thermoplastic polymers due to low melting temperature and wide temperature range of mesophase.

\section{Acknowledgments}

The author thanks Professor H. Reynaers and Dr. B. Goderis from Catholic University of Leuven for help during synchrotron measurements and fruitful discussion.

\section{References}

[1] G. Costa, D. Meli, Y. Song, A. Turturro, B. Valenti, M. Castellano, L. Falqui, Polymer 42, 8035 (2001).

[2] J.C. Ho, K-H. Wei, J. Polym. Sci., Polym. Phys. Ed. 38, 2124 (2001).

[3] J.C. Ho, K.H. Wei, Macromolecules 33, 5181 (2000).

[4] H. Hakeni, Polymer 41, 6145 (2000).

[5] B. Liang, L. Pan, X. He, J. Appl. Polym. Sci. 66, 217 (1997).

[6] M. Pracella, D. Danielli, E. Chielini, Macromol. Chem. 187, 2387 (1986).

[7] W. Brostow, Polymer 31, 979 (1990).

[8] T. Miteva, L. Minkova, P. L. Magagnini, Macromol. Chem. Phys. 199, 1519 (1998).

[9] M.H.J. Koch, J. Bordas, Nucl. Instrum. Methods 208, 461 (1985).

[10] C.J. Boulin, R. Kempf, A. Gabriel, M.H.J. Koch, Nucl. Instrum. Methods Phys. Res. A 357, 178 (1995).

[11] J. Grebowicz, B. Wunderlich, J. Polym. Sci., Polym. Phys. Ed. 21, 141 (1983). 